\title{
Effects of different soaking time and heating methods on the tenderness of mutton
}

\author{
Lei ZHANG ${ }^{1}$, Lingming $\mathrm{KONG}^{1 \star}$ (D), Danya $\mathrm{XV}^{1}$, Yunqi JIAO ${ }^{1}$
}

\begin{abstract}
In the process of heating the mutton, the length of the soaking time will affect the meat tenderness, and the proper change of the soaking time can improve the meat tenderness. The sample was treated by water bath and microwave heating method, and the cooking loss rate, collagen solubility, shear force and the like were used as indicators for measuring tenderness. The effect of different soaking time on the tenderness of mutton was studied under water bath and microwave heating. The prolonged incubation time, the total soluble protein, collagen solubility and cooking loss of the meat treated by water bath were significantly increased $(P<0.01)$; while the myofibrillar protein and shear force values showed a downward trend. The difference in soaking time has an effect on the meat tenderness. Extending the soaking time, the color of the $20 \mu$ strip gradually deepened, and the $32 \mu$ and $75 \mu$ strips showed different degrees of weakening. This indicates that the protein is degraded and the myofiber structure of the meat is destroyed. This provides a theoretical basis for the production and processing of enterprises and the table culture of the people.
\end{abstract}

Keywords: mutton; muscle; tenderness; SDS-PAGE; SEM.

Practical application: There were different small-molecule peptides in different treatment groups, the proteins were degraded to a certain extent, the myofiber structure was destroyed, and the basic structure was changed.

\section{Introduction}

Meat and meat products, especially high-quality animal proteins in meat, are indispensable in daily diet of human beings (Mao et al., 2012; Li et al., 2013; Ding \& Xiao, 2014). In the process of selecting meat products, people always subjectively judge the quality of meat products based on their sensory characteristics, such as the appearance, water holding capacity, tenderness, and texture (Zheng et al., 2012). At present, there are only a few studies on the improvement of tenderness of mutton, as well as the effect of different soaking time on tenderness of mutton around the world. Walsh et al. (2010) showed that when the center of the meat reached a certain temperature and kept for a while, the cooking loss rate increased significantly, and the muscle tenderness decreased; Combes et al. also showed that with the prolonging of the soaking time, the shear force of muscle increased (Me, 2016); while Vasanthi believed that different temperature and soaking time would reduce muscle shear force and improve the meat tenderness due to the gelation of collagen. Some studies have shown that the proper prolonging of soaking time under the temperature of $50-60{ }^{\circ} \mathrm{C}$ could improve the tenderness of duck meat to a certain extent, which was believed to be caused by the dissolution of collagen in the meat. However, there is only a small correlation between the solubility and tenderness of collagen, and most studies have not considered the importance of myofibril on meat tenderness.

Meat tenderness is an important indicator for evaluating meat quality (Feng et al., 2009), and helping the consumers to select meat products (Lawrie, 1981). Therefore, scholars at home and abroad have been focusing on the improvement of meat tenderness and full tenderization of meat products. Meat tenderness has been determined through sensory evaluation, which is simple and easy to operate and can be fully close to the actual sense of taste, but due to the strong professionalism, large sample size, large differences in regions and personal preferences, and lack of a certain theoretical basis (Paglarini et al., 2020; Vidal et al., 2020). There are some problems in difference, reliability and comparability of experimental results. Therefore, with the development of the instruments such as Texture Profile Analysis (TPA) and physical property instrument, the more accurate analysis on meat quality based on quantitative data can be performed (Zhou et al., 2003; Palka \& Daun, 1999; Rocha-Garza \& Zayas, 1996), and the evaluation system of meat products has been constantly improved.

In this study, the effects of low-voltage electrical stimulation on the glycolysis process during the maturation process were clarified, and the mechanism of action was explored in combination with SDS-PAGE electrophoresis analysis and ESM observation of myofibril ultrastructure on the basis of the studies on the concentration of soluble protein (CSP), myofibril fragmentation index (MFI), and collagen solubility (CS) of mutton (longissimus dorsi and semitendinosus). Due to the differences in instruments, the results of shear force (SF), one of the commonly used indexes for measuring meat tenderness, were also different. Some researchers proposed that the structure of myofibrils and connective tissues (Li et al., 2006a), myofibril fragmentation index (MFI), collagen solubility (Hill, 1966), myofiber diameter quantification (Locker, 1960; Locker \& Hagyard, 1963; 
Locker, 1985; Koohmaraie et al., 2002; Wattanachant et al., 2005; White et al., 2006), and changes in sarcomere length could be taken as the indicators measuring meat tenderization (Purslow, 2005; Joo et al., 1999), but no quantitative index analysis on the structural changes of myofibrils and connective tissues has been conducted so far. Due to the large difference in data measured by various measurement methods, the myofibril fragmentation index cannot be systematically analyzed; the quantitative analysis on collagen solubility cannot be conducted either; there are still disputes on the changes in myofiber diameter and sarcomere length. Therefore, the analysis based on shear force is more consistent currently, and shear force can also be taken as one of the indicators to analyze and judge the tenderness of meat.

\section{Materials and instruments}

\subsection{Materials and reagents}

Healthy and disease-free Kazakh sheep (36-36 months old, $45 \mathrm{~kg} \pm 5 \mathrm{~kg}$ ) were randomly selected from Hami Prefecture, Xinjiang. The meat samples of $3.0 \times 3.0 \times 3.0 \mathrm{~cm}$ in size and $70 \pm 5 \mathrm{~g}$ in weight were randomized into 12 groups, with 4 meat samples in each group. The prepared meat samples in a certain volume were placed into vacuum bags, and heated to the required target temperature: 60,80 and $100{ }^{\circ} \mathrm{C}$, under which, the samples were treated by certain measures; the values at 0 , 10,30 and $60 \mathrm{~min}$ were selected to study ( $0 \mathrm{~min}$ was taken as the control group, and no soaking treatment was performed). The digital thermometers were used during the entire heating process to monitoring the soaking temperature, and when the soaking time was reached, the samples were immediately taken out anhydrous treatment and finally weighed.

Reagents: Potassium iodide, $\mathrm{KH}_{2} \mathrm{PO}_{4}, \mathrm{~K}_{2} \mathrm{HPO}_{4}, \mathrm{KCl}$ (analytically pure), Tianjin Fuchen Chemicals Reagent Factory; potassium phosphate, EGTA, and glutaraldehyde, Tianjin Zhiyuan Chemical Reagent Co., Ltd.

\subsection{Instruments and equipment}

PL203 electronic balance, Mettler Toledo Instruments (Shanghai) Co., Ltd.; DZKW-S-6 Electric-Heated Thermostatic Water Bath, Beijing Yongguangming Medical Treatment Instrument Factory; DHG-9140A Electrothermal Blowing Dry Box, Shanghai Yiheng Scientific Instrument Co., Ltd.; TES1310 Digital Thermometer, TES Electric Electronic Corp; pHS-3C Acidimeter, Mettler Toledo Inc.; TA-XT2i Texture Analyzer, Stable Micro System, UK; TDL5-A Low-Speed Desktop Centrifuge, ShangHai Anting Scientific Instrument Factory; FSH-2 Adjustable High-Speed Homogenizer, Jintan Chengdong Xinrui Instrument Factory; DYCZ-24DN Electrophoresis Apparatus, Beijing Liuyi Biotechnology Co., Ltd; SU8010 Electron Scanning Microscope, HITACHI, Japan.

\subsection{Test methods}

Analysis on myogen and the myofibrillar protein

The determination was performed by the methods of Hill (1966); Bergman \& Loxley (1963).
Extraction of myogen: $1 \mathrm{~g}$ of meat was taken from each sample and placed in a $100 \mathrm{~mL}$ centrifuge tube; then $10 \mathrm{~mL}$ of buffer A (ice-bath potassium phosphate: $0.025 \mathrm{~mol} / \mathrm{L}, \mathrm{pH} 7.2$ ) was slowly added for homogenization for $25 \mathrm{~s}$; one minute later, the homogenization was repeated twice, to avoid protein denaturation due to instantaneous temperature rise during homogenization. After extraction for $15 \mathrm{~h}$ at $0-4^{\circ} \mathrm{C}$, the extract was centrifuged at $4500 \mathrm{r} / \mathrm{min}$ for $10 \mathrm{~min}$ to obtain the supernatant, and the biuret method was used to determine the concentration of the protein.

Extraction of total soluble protein: $1 \mathrm{~g}$ of meat was taken and placed in a $100 \mathrm{~mL}$ centrifuge tube; then $10 \mathrm{~mL}$ of buffer $\mathrm{B}$ (ice bath phosphoric acid of $1.1 \mathrm{M}$ potassium iodide dissolved in $0.1 \mathrm{M}$ potassium phosphate, $\mathrm{pH}$ 7.2) was slowly added, and homogenization, extraction, centrifugation and determination were the same as above.

The solubility of myogen and myofibrillar protein respectively represents the percentage of myogen and myofibrillar protein in total meat weight (wet weight), and the sum of myogen and myofibrillar protein is the soluble protein.

\subsection{Analysis on collagen}

The determination was performed by the methods of Honikel (1998) and Li et al. (2006b).

During the nitrification analysis, collagen would be decomposed to produce various amino acids, while the content of hydroxyproline in amino acids was relatively stable (about $13 \%$ ). Therefore, the content of collagen can be indirectly calculated based on the content of the generated hydroxyproline by Formula 1:

Content of collagen $(\mu \mathrm{g})=\frac{\text { Content of hydroxyproline }(\mu \mathrm{g}) \times 7.25 \times 10^{4} \times 20}{\text { Molecular weight of hydroxyproline }} \times 10^{6}$

\subsection{Determination of shear force}

$1 \mathrm{~cm}^{3}$ of meat was cut from each sample as the test sample, to determine the standard of shear force: Probe: HDP/BSW; speed before measurement: $3.00 \mathrm{~mm} / \mathrm{s}$; measurement speed: $3.00 \mathrm{~mm} / \mathrm{s}$; speed after measurement: $20.00 \mathrm{~mm} / \mathrm{s}$; pressing distance: $20 \mathrm{~mm}$; type: Auto- 20 g; data acquisition rate: 500 PPS. The operation was repeated for three times, and the mean was obtained (Schroeder, 2013).

\subsection{Determination of the cooking loss rate}

The test samples were packaged in cooking bags, and then took out when the core temperature of the samples reached about $80^{\circ} \mathrm{C}$; after wiping the excess water on the surface, the samples were cooled to room temperature and weighed. The cooking loss rate was determined referring to the method of Hroeder (2013), and calculated by Formula 2:

Cooking loss rate $(\%)=\frac{\text { Meat weight before cooking }- \text { Meat weight after cooking }}{\text { Meat weight before cooking }} \times 100 \%$

\subsection{SDS-PAGE electrophoresis analysis}

$5 \mathrm{~g}$ of meat sample was weighed, and the temperature was controlled at about $4{ }^{\circ} \mathrm{C}$ with the method of Hill (1966); and 
then $40 \mathrm{~mL}$ of MFI buffer solution $\left(1 \mathrm{mM} / \mathrm{L} \mathrm{MgCl}_{2}, 1 \mathrm{mM} / \mathrm{L}\right.$ $\mathrm{NaN}_{3}, 1 \mathrm{mM} / \mathrm{L}$ EGTA, $8.8 \mathrm{mM} / \mathrm{L} \mathrm{KH}_{2} \mathrm{PO}_{4}, 11.2 \mathrm{mM} / \mathrm{L} \mathrm{K}_{2} \mathrm{HPO}_{4}$, and $100 \mathrm{mM} / \mathrm{L} \mathrm{KCl}$ ) was added; after crushing and shaking, the residue was filtered, and the slurry was taken for centrifugation at $8000 \mathrm{r} / \mathrm{min}$ for $10 \mathrm{~min}$. The suspension was prepared through adding $10 \mathrm{~mL}$ of MFI buffer into the sediment, and then filtered by a 40 -mesh standard sieve. The suspension was mixed with SDS-PAGE loading buffer at a ratio of 5:1, and the mixture was heated for 3-5 min by a boiling water bath; $10 \mu \mathrm{L}$ was taken as the loading volume. The concentration of spacer gel and separation gel was $4 \%$ and $12 \%$ respectively. The initial voltage was set as $80 \mathrm{~V}$, which was adjusted to $140 \mathrm{~V}$ when the protein fully entered into the separation gel. The Coomassie brilliant blue method was used for staining, and then the destaining solution was used for destaining; finally, the clearly visible strips were shot for analysis.

\subsection{SEM analysis}

SEM samples were prepared referring to the method of Nishimura et al. (1999), and slightly modified. The scanning electron microscope (SEM) was used to observe the ultrastructure of myofibers of the test sample. $1 \mathrm{~cm}^{3}$ of meat after heating was taken and placed in $2.5 \%$ glutaraldehyde for standby application.

$0.3 \mathrm{~cm}^{3}$ of meat was cut from the meat sample of $1 \mathrm{~cm}^{3}$, and placed into $2.5 \%$ glutaraldehyde; later, it was washed with PBS ( $\mathrm{pH} 7.3$ ) for three times at $4{ }^{\circ} \mathrm{C}$ and then with phosphate buffer ( $\mathrm{pH} 7.3$ ); gradient dehydration of $50 \%, 70 \%, 80 \%$ and $90 \%$ was performed with ethanol for $15 \mathrm{~min}$, and dehydration with anhydrous ethanol was performed for three times ( $30 \mathrm{~min} /$ time). The dehydrated meat samples were replaced with tert-butanol for $30 \mathrm{~min}$ each time, and then the dehydrated and replaced meat samples were placed on the sample table for coating with a sputter coater. The 2,000, 3,000, 20,000, and 50,000 SEMs (voltage: $5.0 \mathrm{kV}$ ) were used to observe and analyze the overall structure of the muscle and the changes in endomysium and perimysium.

\subsection{Data analysis}

The test data were statistically analyzed by Excel 2003 and SPSS 21.0. The indicators, including shear force, were analyzed by Exponent of the Stable Micro System.

\section{Results}

\subsection{Changes in total soluble protein under different soaking time}

As for longissimus dorsi and semitendinosus after water bath heating under different soaking time, with the prolonging of the soaking time under certain conditions, the changes in total soluble protein were basically the same.

The total soluble protein in the meat sample heated at $60^{\circ} \mathrm{C}$ without soaking was higher than that in meat samples heated at $80^{\circ} \mathrm{C}$ and $100^{\circ} \mathrm{C}$. After prolonging the soaking time under certain conditions, the soluble proteins showed a downward trend $(P<0.01)$ (Figure 1$)$.

\subsection{Changes of solubility of sarcoplasmic proteins under different soaking time}

As for longissimus dorsi and semitendinosus after water bath heating at $60{ }^{\circ} \mathrm{C}$ under different soaking time, with the prolonging of the soaking time under certain conditions, the solubility of sarcoplasmic proteins significantly decreased $(P<0.05)$, then increased, and significantly decreased again $(P<0.01)$. At this time, it was approximately equal to the solubility of sarcoplasmic proteins at $80^{\circ} \mathrm{C}$.

The comprehensive analysis showed that the prolonging of soaking time and increase of core temperature played a certain role in reducing the solubility of sarcoplasmic proteins (Figure 2).

\subsection{Changes of myofibrillar protein solubility under different soaking time}

As for longissimus dorsi and semitendinosus after water bath heating at $60^{\circ} \mathrm{C}$ under different soaking time, with the prolonging of the soaking time under certain conditions, the myofibrillar protein solubility showed a significant downward trend $(P<0.01)$, and reached near the minimum value; at $80{ }^{\circ} \mathrm{C}$, with the prolonging of the soaking time under certain conditions, the myofibrillar

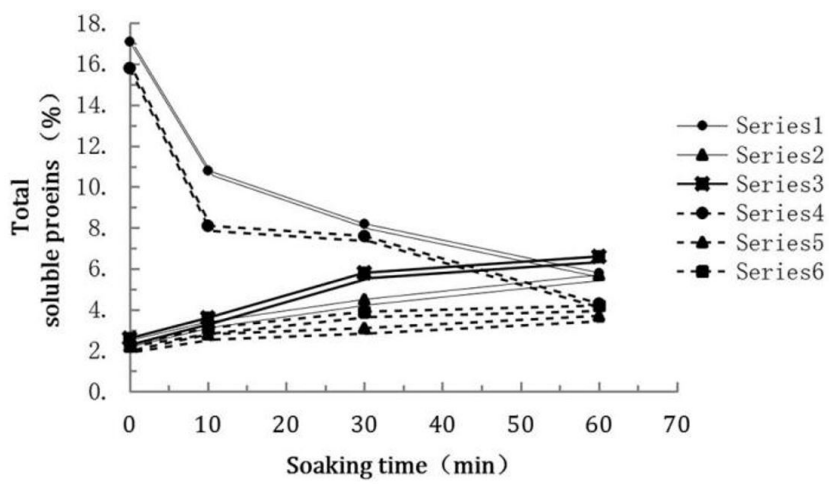

Figure 1. Changes of total soluble proteins under different soaking time (mean \pm standard deviation, $\mathrm{n}=4$ ).

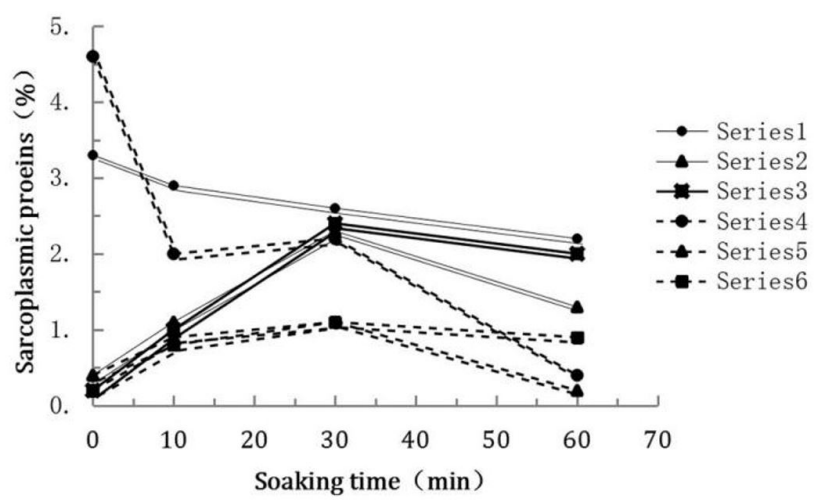

Figure 2. Changes of solubility of sarcoplasmic proteins under different soaking time (mean \pm standard deviation, $\mathrm{n}=4$ ). 
protein solubility of longissimus dorsi and semitendinosus showed an upward trend with the prolonging of soaking time, but the trend was not significant $(P>0.05)$ (Figure 3 ).

\subsection{Changes of collagen solubility under different soaking time}

As for longissimus dorsi after water bath heating at $60{ }^{\circ} \mathrm{C}$ under different soaking time, with the prolonging of the soaking time under certain conditions, the collagen solubility of longissimus dorsi after water bath and microwave heating showed an increasing trend; at $100{ }^{\circ} \mathrm{C}$, with the prolonging of the soaking time under certain conditions, the collagen solubility first significantly increased $(P<0.05)$, and then there was no significant change $(P>0.05)$; compared with water bath heating, the overall change in collagen solubility after microwave treatment was not significant $(P>0.05)$ (Figure 4$)$.

As for semitendinosus after water bath and microwave heating under different soaking time, with the prolonging of the soaking time under certain conditions, the collagen solubility basically showed a trend of gradual increase. At $60^{\circ} \mathrm{C}$, with the prolonging of the soaking time under certain conditions, the collagen solubility first increased significantly $(P<0.05)$, and then the change trend was no longer significant $(P>0.05)$; at $80^{\circ} \mathrm{C}$, with the prolonging of the soaking time under certain conditions, the

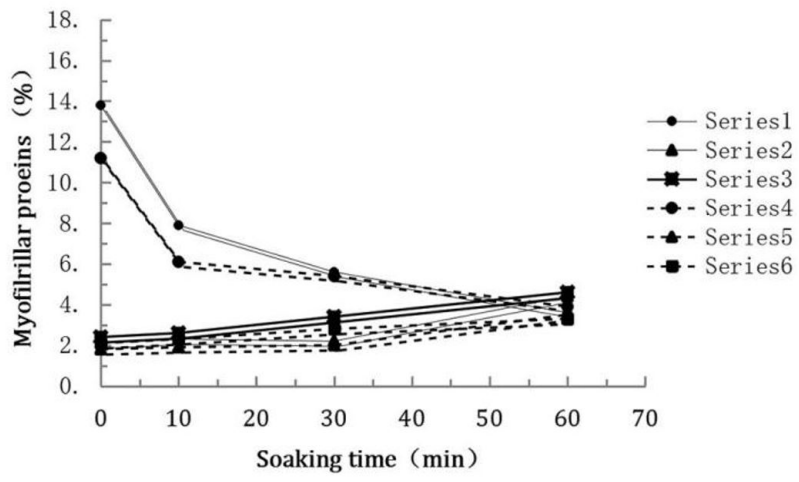

Figure 3. Changes of myofibrillar protein solubility under different soaking time (mean \pm standard deviation, $\mathrm{n}=4$ ).

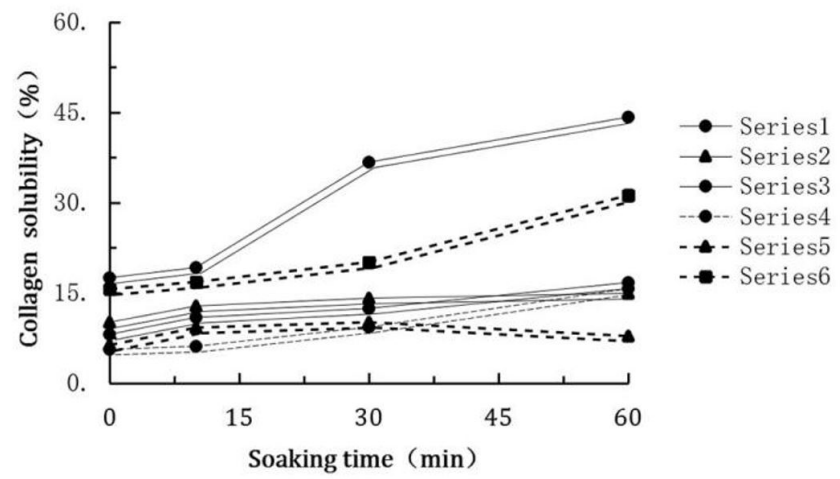

Figure 4. Changes of collagen solubility in longissimus dorsi under different soaking time (mean \pm standard deviation, $\mathrm{n}=4$ ). collagen solubility was basically unchanged $(P>0.05)$; at $100^{\circ} \mathrm{C}$, with the prolonging of the soaking time under certain conditions, the collagen solubility increased significantly $(P<0.01)$, with a significant increasing trend $(P<0.05)$.

Under different soaking time, with the prolonging of the soaking time under certain conditions, the collagen solubility of semitendinosus after microwave treatment did not change significantly $(P>0.05)$.

Under different soaking time, the proper prolonging of soaking time could dissolve the collagen, which was basically the same as the results of previous studies. The change in collagen solubility could tenderize the meat to a large extent (Swatland, 2006; Xia et al., 2014) (Figure 5).

\subsection{Changes of the cooking loss rate under different soaking time}

As shown in Figure 6, as for semitendinosus and longissimus dorsi after microwave heating, the cooking loss rate was higher than water bath heating. As for longissimus dorsi after microwave and water bath heating, with the prolonging of the soaking time under certain conditions, the cooking loss rate showed a certain trend of increase.

Under different soaking time, as for semitendinosus after water bath heating at $60^{\circ} \mathrm{C}$, with the prolonging of the soaking time under certain conditions, the increase in the cooking loss rate was not significant $(P>0.05)$; at $80^{\circ} \mathrm{C}$, with the prolonging of the soaking time under certain conditions, the cooking loss rate extremely significantly increased $(P<0.01)$; at $100^{\circ} \mathrm{C}$, with the prolonging of the soaking time under certain conditions, the cooking loss rate was basically unchanged.

Under different soaking time, as for the semitendinosus after microwave heating at $60^{\circ} \mathrm{C}$, with the prolonging of the soaking time under certain conditions, the cooking loss rate increased significantly $(P<0.05)$; at $80-100{ }^{\circ} \mathrm{C}$, with the prolonging of the soaking time under certain conditions, the increase in the cooking loss rate was not significant $(P>0.05)$. When the core temperature reached about $100{ }^{\circ} \mathrm{C}$, with the prolonging of the soaking time under certain conditions, the cooking loss rate was basically unchanged.

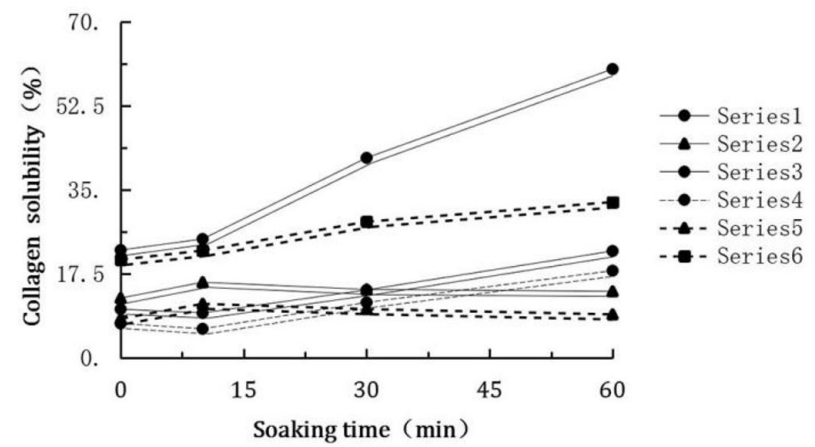

Figure 5. Changes of semitendinosus collagen solubility under different soaking time (mean \pm standard deviation, $\mathrm{n}=4$ ). 

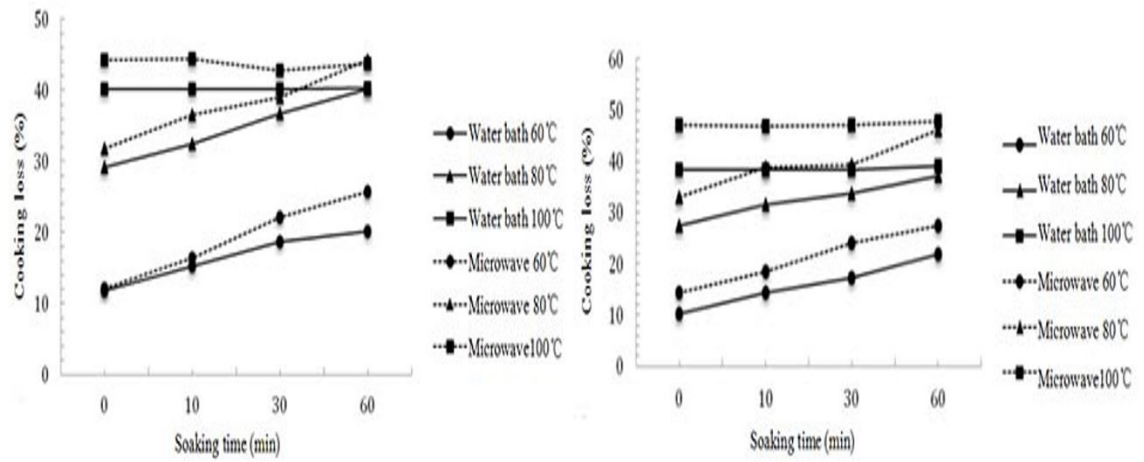

Figure 6. Changes of cooking loss rate of semitendinosus and longissimus dorsi under different soaking time $($ mean \pm standard deviation, $\mathrm{n}=4$ ).
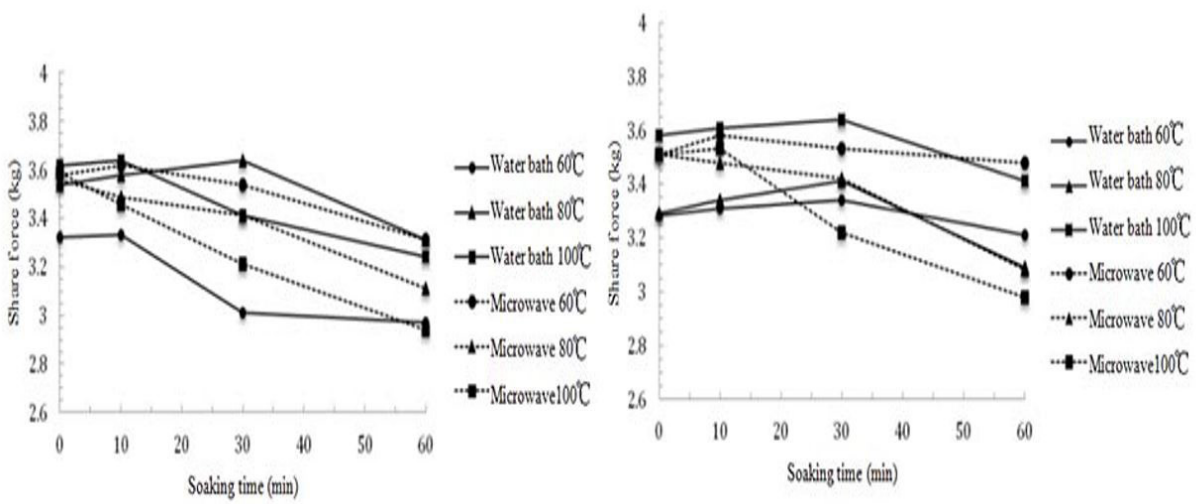

Figure 7. Changes of shear force of semitendinosus and longissimus dorsi under different soaking time $($ mean \pm standard deviation, $\mathrm{n}=4)$.

Under different soaking time, as for longissimus dorsi after microwave heating at $60^{\circ} \mathrm{C}$, with the prolonging of the soaking time under certain conditions, the cooking loss rate first increased significantly $(P<0.05)$ and then changed slightly $(P>0.05)$; at $80^{\circ} \mathrm{C}$, with the prolonging of the soaking time under certain conditions, the cooking loss rate first changed slightly and then increased significantly $(P<0.05)$; at $100^{\circ} \mathrm{C}$, with the prolonging of the soaking time under certain conditions, the cooking loss rate was basically unchanged (Figure 6).

\subsection{Changes of shear force under different soaking time}

Under different soaking time, as for the semitendinosus after water bath heating at $60^{\circ} \mathrm{C}$ and $100^{\circ} \mathrm{C}$, with the prolonging of the soaking time under certain conditions, the shear force first changed slightly $(P>0.05)$ and then significantly decreased $(P<0.05)$ and had no significant change $(P>$ $0.05)$; at $80^{\circ} \mathrm{C}$, with the prolonging of the soaking time under certain conditions, the shear force first increased and then significantly decreased $(P<0.05)$; as for longissimus dorsi after microwave heating at $60-100{ }^{\circ} \mathrm{C}$, with the prolonging of the soaking time under certain conditions, the shear force showed a trent of decrease, but the change was not significant $(P>0.05)$ (Figure 7).

Under different soaking time, as for longissimus dorsi after water bath heating at $60{ }^{\circ} \mathrm{C}$, with the prolonging of the soaking time under certain conditions, the shear force had no significant change $(P>0.05)$; at $80-100^{\circ} \mathrm{C}$, the shear force first slowly decreased and then significantly decreased $(P<0.05)$.

As for longissimus dorsi after microwave heating at $60-100^{\circ} \mathrm{C}$, with the prolonging of the soaking time under certain conditions, the change was not significant, and only in the case of microwave heating at $100{ }^{\circ} \mathrm{C}$, and soaking for $30 \mathrm{~min}$, the shear force significantly decreased $(P<0.05)$.

The shear force of longissimus dorsi showed a trend of decrease at certain temperature and under certain soaking time, indicating the dissociation of actomyosins, which can reduce the shear force and improve the meat tenderness. It can be concluded that the prolonging of the soaking time and control of temperature can improve the tenderness of meat products to a certain extent.

\subsection{Changes of myofiber diameter and sarcomere length under different soaking time}

Under different soaking time, as for semitendinosus after water bath heating at $60{ }^{\circ} \mathrm{C}$, with the prolonging of the soaking time under certain conditions, the myofiber diameter first decreased, which was not significant $(P>0.05)$, and then significantly increased; at $80-100{ }^{\circ} \mathrm{C}$, the myofiber diameter gradually decreased with the prolonging of the soaking time $(P<0.01)$. 
Under different soaking time, as for the semitendinosus after water bath heating at $60{ }^{\circ} \mathrm{C}$, with the prolonging of the soaking time under certain conditions, the sarcomere length first significantly increased $(P<0.01)$, and then decreased and increased again; at $60^{\circ} \mathrm{C}$, the sarcomere length showed a trend of increase; at $80^{\circ} \mathrm{C}$, with the prolonging of the soaking time under certain conditions, the sarcomere length extremely significantly decreased $(P<0.01)$; at $100^{\circ} \mathrm{C}$, with the prolonging of the soaking time under certain conditions, the overall increase of sarcomere length was not significant $(P>0.05)$; and under different soaking time, the sarcomere length of the meat sample at $80^{\circ} \mathrm{C}$ was significantly greater than that of the meat sample at $100{ }^{\circ} \mathrm{C}(P<0.01)$ (Figure 8$)$.

\subsection{SDS-PAGE analysis under different soaking time}

The degradation of skeleton protein would lead to physical and chemical changes in myofibrils, such as the rupture at the junction of the $\mathrm{Z}$ disc and I strip and myofibril fragmentation, which would destroy the microstructure of the cells, and ultimately improve meat tenderness to a certain extent (Wu et al., 2016; Mao et al., 2016). The peptide fragments $28 \mu$ and $32 \mu$ are the signs of protein hydrolysate, and also important factors for improving the meat tenderness (Claeys et al., 1995; Patrascu et al., 2013) (Figure 9).

Desmin could connect myofibrils and maintain certain structure of cells, and it is also a type of skeleton protein between
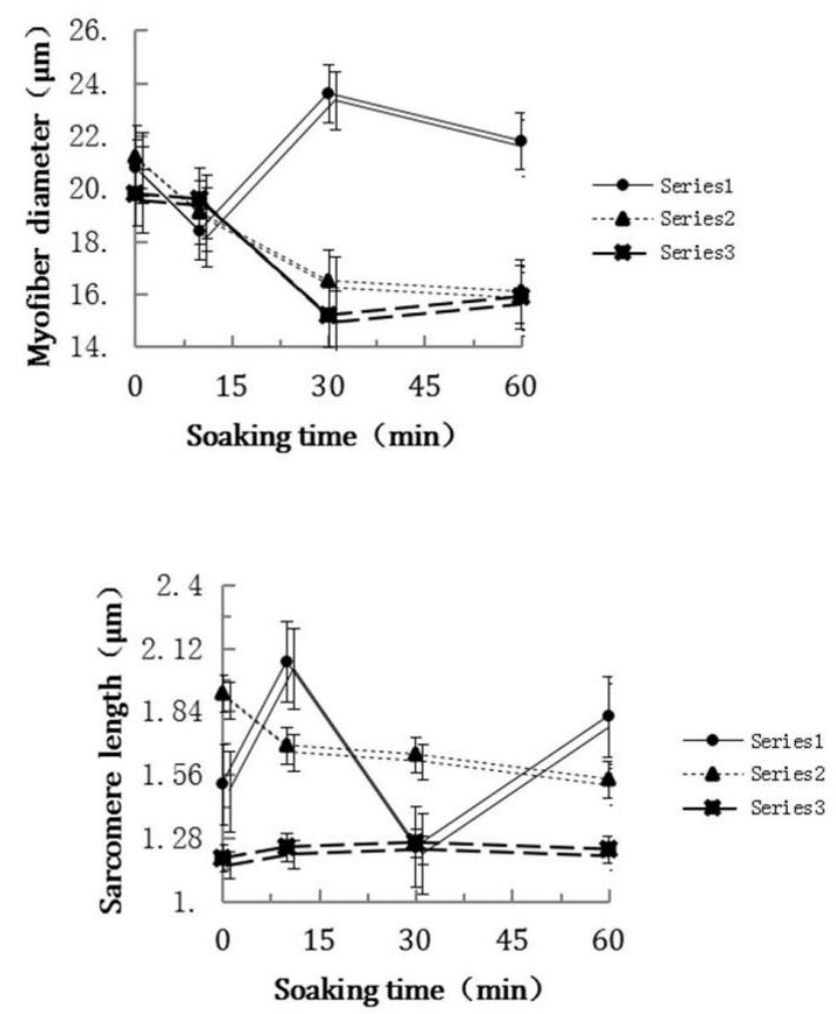

Figure 8. Changes of semitendinosus, myofiber diameter and sarcomere length under different soaking time after water bath (mean \pm standard deviation, $\mathrm{n}=4$ ). two Z lines of myofibrils. The degradation and disappearance of desmin would directly cause rupture of myofibers and separation of sarcomere, and increase the myofibril fragmentation index, thus improving the water holding capacity of meat and tenderizing the meat (Dong et al., 2014; Chen et al., 2012).

The combination of tropomyosin and troponin would create troponin $\mathrm{T}$ subunits, whose degradation would affect the binding of myosin and actin, and thus improving the water holding capacity of meat and tenderizing the meat. At the same time, their degradation would also produce $28 \mu$ peptide chain, as shown in Figure 10.

The heated longissimus dorsi sample was selected and observed under SDS, and the results showed that with the prolonging of the soaking time under certain conditions, the desmin strips and troponin T strips gradually faded. At $60{ }^{\circ} \mathrm{C}$, the strips gradually faded, and $32 \mu$ strips became darker from clear with the prolonging of soaking time; at $80^{\circ} \mathrm{C}$, the strips first appeared faintly and then faded; at $100^{\circ} \mathrm{C}$, the colors of 20,28 and $32 \mu$ strips were all gradually deepened, which indicated that different soaking time would affect the tenderness of mutton, and the proper prolonging of soaking time would play a certain role in tenderizing the meat. Another sign of mutton tenderization is the appearance of $20 \mu$ strips due to the degradation of longer-chain proteins (Figure 11).

\subsection{Observation and analysis with a scanning electron microscope under different soaking time}

Through determining the above indicators, the semitendinosus after heating was selected for observation under a scanning electron microscope at the amplification of 3,000 and 50,000 times.

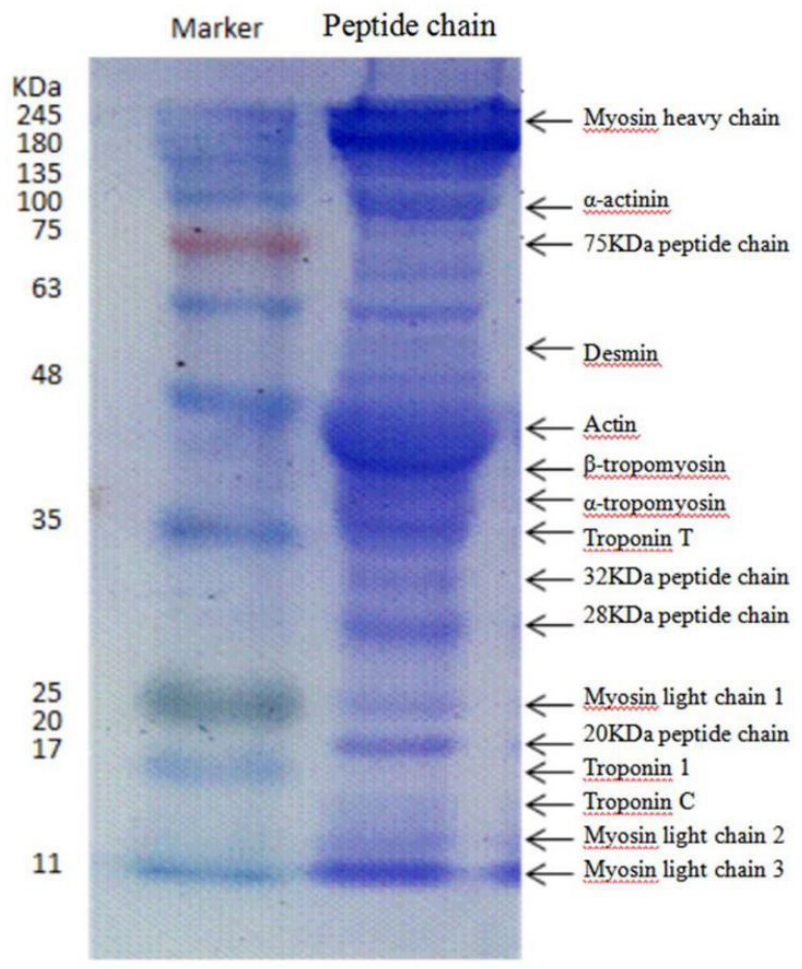

Figure 9. Distribution of myofibril protein strips. 

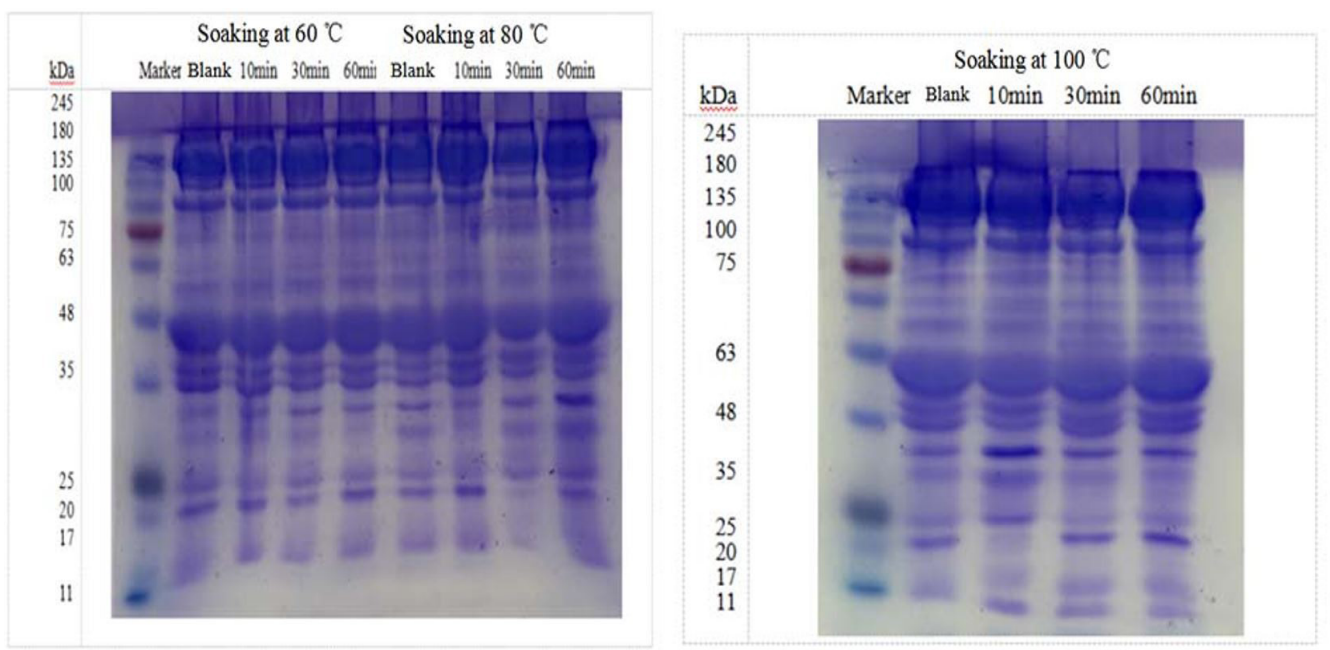

Figure 10. Effect of water bath heating of semitendinosus under different soaking time on skeleton protein degradation.
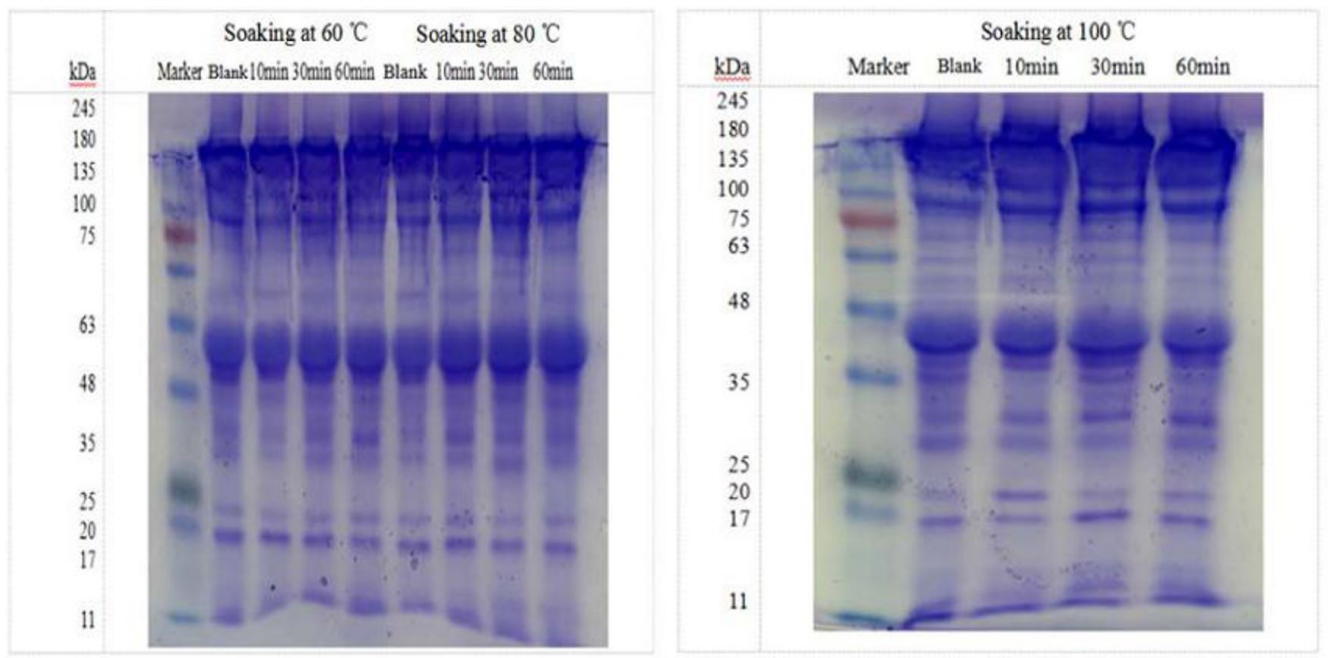

Figure 11. Effect of water bath heating of longissimus dorsi under different soaking time on skeleton protein degradation.

The results showed that when the heating temperature reached $60{ }^{\circ} \mathrm{C}$, the prolonging of the soaking time under certain conditions would make the cross-section of myofibril contract severely, narrow the space between myofibers, and tighten the texture of myofibers. After keeping the core temperature within $80-100^{\circ} \mathrm{C}$ for a certain period of time, there was also the same change in myofibers, but the contraction between myofibers was more obvious, and the space between myofibers completely disappeared (Figure 12).

The longitudinal section of the test meat sample was magnified 2,000 and 20,000 times under a scanning electron microscope for observation. The results showed that when the heating temperature reached $60{ }^{\circ} \mathrm{C}$, the sarcomere gradually became clear with the increase of the soaking time; and the sarcomere length was the most visible under $80^{\circ} \mathrm{C}$ for $30 \mathrm{~min}$. When the soaking time was prolonged to $60 \mathrm{~min}$, the structure of $\mathrm{Z}$ disc was gradually destroyed; and when the core temperature reached $100{ }^{\circ} \mathrm{C}$, the overall structure of the sarcomere was damaged, showing a flocculent structure (Figure 13).

\section{Discussion}

Mutton is a kind of health food with high protein, low fat and low cholesterol. It is rich in a variety of amino acids and trace elements needed by human body. It is widely loved by consumers because of its tender meat and delicious taste. Moreover, mutton also has certain biological effects, including the functions of keeping cold, strengthening spleen, invigorating qi and keeping fit.

Tenderness is one of the most important eating qualities for consumers, which represents the tenderness of meat during chewing, and is an important index reflecting the texture of meat products. Mutton is a kind of perishable food. The researches of mutton storage and preservation technology are of great significance to extend the shelf life of mutton products, broaden the sales mode and sales radius, even the future development of mutton industry. With the improvement of living standards, consumers prefer fresh and delicious meat products with natural flavor, and the requirements of preservation technology are more stringent. 

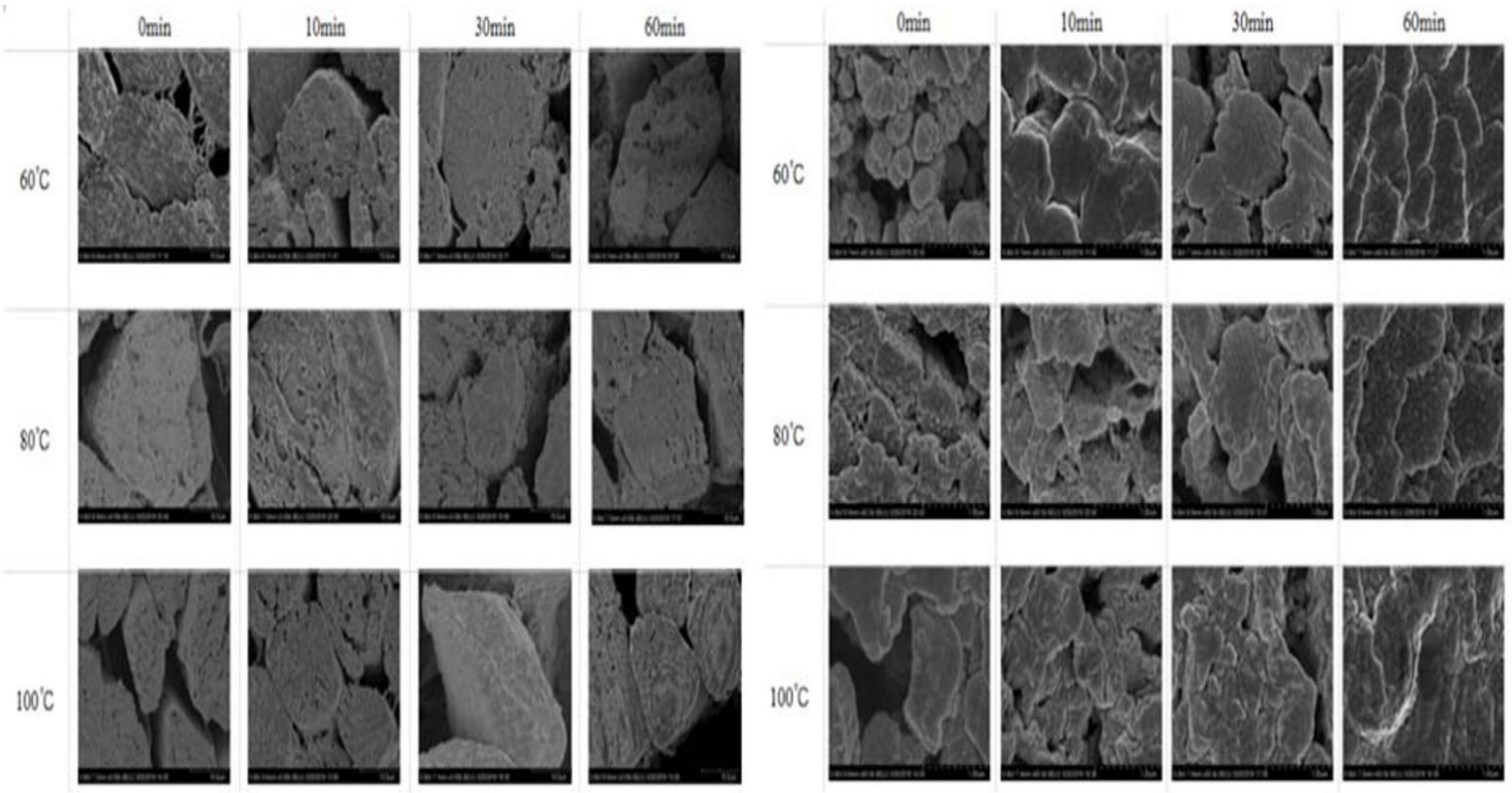

Figure 12. Changes of ultrastructure of fiber under different soaking time and temperature (Cross section $3000 \times$ 'L' and Cross section $50000 \times$ ' $R$ ').
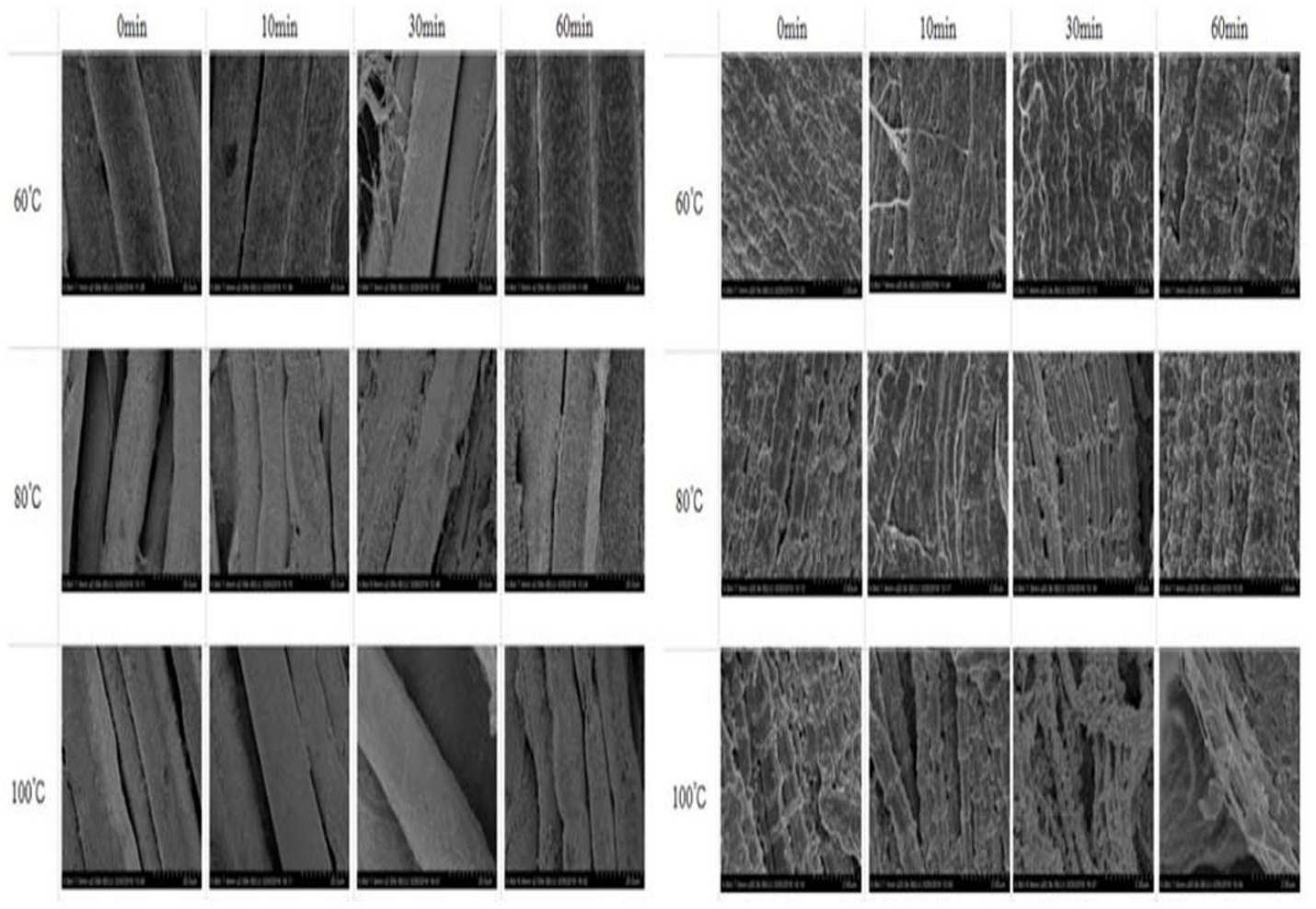

Figure 13. Changes of the ultrastructure myofiber under different soaking time and temperature (Longitudinal section $2000 \times$ 'L' and Longitudinal section $20000 \times$ 'R').

In this study, we found that the prolonging of the soaking time had a significant effect on the total soluble protein in longissimus dorsi and semitendinosus. It also had a significant effect on collagen solubility, which was increased with the prolonging of the soaking time in different treatment groups. The water bath heating group $\left(100^{\circ} \mathrm{C}\right)$ had the most significant trend of increase, which was consistent with the conclusion of Combes (Lu et al., 2015). While the myofibrillar protein and shear force values showed a downward trend, indicating the influence of soaking time on the meat tenderness. In other words, it could tenderize the meat to a certain extent. Through correspondingly prolonging the holding time, the cooking loss 
rate of meat was significantly increased. The cooking loss rate of meat treated by microwave heating was higher than that of meat treated by water bath heating.

The results showed that the cooking loss, protein degradation index and myofibrillar protein gel strength of beach mutton increased gradually with the increase of heating temperature. This was also consistent with the changing trend of meat quality in producing and processing. Moderate heat processing could improve the tenderness and taste of products, but the structure of protein was destroyed seriously by over heat processing, such as high temperature sterilization, resulting in the serious decline of water retention, taste and other quality of products.

\section{Conclusion}

After prolonging the soaking time under certain conditions, the color of $20 \mu$ strips gradually deepened, and $32 \mu$ and $75 \mu$ strips also showed different degrees of weakening. This is basically similar to the conclusion of a previous study (Swatland, 2006), indicating that there were different small-molecule peptides in different treatment groups, the proteins were degraded to a certain extent, the myofiber structure was destroyed, and the basic structure was changed.

\section{Abbreviations}

TPA: texture profile analysis. CSP: concentration of soluble protein. MFI: myofibril fragmentation index. CS: collagen solubility. SF: shear force. SEM: Scanning electron microscope.

\section{Ethical approval}

This article does not contain any studies with human participants or animals performed by any of the authors.

\section{Funding}

The research was financially supported by the National Natural Science Foundation of China (No. 31660440).

\section{Conflict of interest}

There are no potential conflicts of interest to disclose.

\section{Author Contributions}

Lei Zhang is resposible for the literature research, experimental studies, data analysis, manuscript preparation. Lingming Kong is resposible for the guarantor of integrity of the entire study, study concepts \& design, definition of intellectual content, literature research, experimental studies, manuscript review. Danya Xv is resposible for the literature research, experimental studies, data acquisition, data analysis, manuscript preparation \& editing. Yunqi Jiao is resposible for the experimental studies, data acquisition, statistical analysis, manuscript preparation \& editing. All authors read and approved the final manuscript.

\section{References}

Bergman, I., \& Loxley, R. T. (1963). Two Improved and simplified methods for spectrophotometric determination of hydroxyproline.
Analytical Chemistry, 35(12), 1961-1965. http://dx.doi.org/10.1021/ ac60205a053.

Chen, Y. L., Zhu, X. S., Yang, S. S., \& Xiao, X. L. (2012). Factors affecting meat tenderness and tenderization methods. Meat Industry, 3, 48-50.

Claeys, E., Uytterhaegen, L., Buts, B., \& Demeyer, D. (1995). Quantification of beef myofibrillar proteins by SDS-PAGE. Meat Science, 39(2), 177-193. http://dx.doi.org/10.1016/0309-1740(94) P1819-H. PMid:22059824.

Ding, L. N., \& Xiao, H. F. (2014). Factors affecting the supply and demand of mutton in China and future trends-analysis and prediction based on partial equilibrium model. Journal of Agrotechnical Economics, 9, 22-31.

Dong, L., Liu, D. Y., Tan, Y., Wang, L. T., Deng, Y. M., Wang, J. Y., \& Wang, N. (2014). Advances in methods for evaluating the eating quality of meat products. Meat Research, 3, 32-37.

Feng, X. C., Xu, X. L., \& Zhou, G. H. (2009). Application of proteomics in meat science. Food Science, 30, 273-277.

Hill, F. (1966). The solubility of intramuscular collagen in meat animals of various ages. Journal of Food Science, 31(2), 161-166. http://dx.doi. org/10.1111/j.1365-2621.1966.tb00472.x.

Honikel, K. O. (1998). Reference methods for the assessment of physical characteristics of meat. Meat Science, 49(4), 447-457. http://dx.doi. org/10.1016/S0309-1740(98)00034-5. PMid:22060626.

Hroeder, D. J. (2013). Elfect of vacuum tumbling time, salt leve1 and phosphate alter natives on processing characteristic of natural deli-tyle turkey breast. Christchurch:Lincoln University of Nebraska, 2, 8-36.

Joo, S. T., Kauffman, R. G., Kim, B. C., \& Park, G. B. (1999). The relationship of sarcoplasmic and myofibrillar protein solubility to colour and water-holding capacity in porcine longissimus muscle. Meat Science, 52(3), 291-297. http://dx.doi.org/10.1016/S03091740(99)00005-4. PMid:22062578.

Koohmaraie, M., Kent, M. P., Shackelford, S. D., Veiseth, E., \& Wheeler T. L. (2002). Meat tenderness and muscle growth: is there any relationships. Meat Science, 62(3), 345-352. http://dx.doi.org/10.1016/ S0309-1740(02)00127-4. PMid:22061610.

Lawrie, R. (1981). Developments in meat science-2. London: Elsevier Applied Science.

Li Y. L, Zhou H. Y, Shen L., Sheng, J. P., \& Wu, X. R. (2006a). Investigation on beef- tenderizing by ficin and papain. Meat Industry, (11), 31-33.

Li, C. B., Chen, Y. J., Xu, X. L., Huang, M., Hu, T. J., \& Zhou, G. H. (2006b). Effects of low-voltage electrical stimulation and rapid chilling on meat quality characteristics of Chinese Yellow crossbred bulls. Meat Science, 72(1), 9-17. http://dx.doi.org/10.1016/j.meatsci.2005.04.035. PMid:20416844.

Li, J., Zhang, Y. K., Suyouli, X., \& Wang, H. (2013). The Analyst of mutton sheep scale raising and mutton production in Xinjiang. Grass-Feeding Livestock, 1, 1-8.

Locker, R. H. (1960). Degree of muscular contraction as a factor in tenderness of beef. Journal of Food Science, 25(2), 304-307. http:// dx.doi.org/10.1111/j.1365-2621.1960.tb00335.x.

Locker, R. H. (1985). Cold-induced toughness of meat. In A. M. Pearson \& T. R. Dutson (Eds.), Advances in meat research (pp. 1-44). Amsterdam: Springer Netherlands.

Locker, R. H., \& Hagyard, C. J. (1963). A cold shortening effect in beef muscles. Journal of the Science of Food and Agriculture, 14(11), 787793. http://dx.doi.org/10.1002/jsfa.2740141103.

Mao, J. W., Xu, H. Z., \& Zhao, Y. J. (2012). Development status of highend mutton and key production technologies. Heilongiiang Animal Science and veterinary. Medicine, 3, 64-65. 
Mao, Y. W., Zhang, Y. M., Zhu, L. X., Liang, R. R., Dong, P. C., \& Luo, $\mathrm{X}$. (2016). Beef and mutton production and consumers' requirement in China. Food and Fermentation Industries, 42, 244-251.

Me, E. Y. (2016). Research on Factors Affecting the Quality of Mutton. Chinese Journal of Animal Husbandry and Veterinary Science and Technology Information, 2, 16-17.

Nishimura, T., Hattori, A., \& Takahashi, K. (1999). Structural changes in intramuscular connective tissue during the fattening of Japanese black cattle: effect of marbling on beef tenderization. Journal of Animal Science, 77(1), 93-104. http://dx.doi.org/10.2527/1999.77193x. PMid:10064032.

Paglarini, C. S., Vidal, V. A. S., Dos Santos, M., Coimbra, L. O., Esmerino, E. A., Cruz, A. G., \& Pollonio, M. A. R. (2020). Using dynamic sensory techniques to determine drivers of liking in sodium and fat-reduced Bologna sausage containing functional emulsion gels. Food Research International, 132, 109066. http://dx.doi.org/10.1016/j. foodres.2020.109066. PMid:32331676.

Palka, K., \& Daun, H. (1999). Changes in texture, cooking losses, and myofibrillar structure of bovine M. semitendinosus during heating. Meat Science, 51(3), 237-243. http://dx.doi.org/10.1016/S03091740(98)00119-3. PMid:22061858.

Patrascu, L., Dobre, I., \& Alexe, P. (2013). Effect of tumbling time, injection rate and k-carrageenan addition on processing, textural and color characteristics of pork biceps femoris muscle. Annals of the University Dunarea de Jos of Galati Fascicle VI. Food Technology, 37(1), 69-84

Purslow, P. P. (2005). Intramuscular connective tissue and its role in meat quality. Meat Science, 70(3), 435-447. http://dx.doi.org/10.1016/j. meatsci.2004.06.028. PMid:22063743.

Rocha-Garza, A. E., \& Zayas, J. F. (1996). Quality of broiler beef patties supplemented with wheat germ protein flour. Journal of Food Science, 61(2), 418-421. http://dx.doi.org/10.1111/j.1365-2621.1996.tb14207.x.

Schroeder, D. J. (2013). Effect of vacuum tumbling time, salt leve1 and phosphate alter natives on processing characteristic of natural deli-tyle turkey breast (Ph.D. thesis). Lincoln University of Nebraska, Lincoln.

Swatland, H. J. (2006). Thermal denaturation of bovine longissimus thoracis aponeurosis, correlating contraction with optical changes.
Canadian Journal of Animal Science, 86(2), 221-224. http://dx.doi. org/10.4141/A06-006.

Vidal, V. A. S., Santana, J. B., Paglarini, C. S., da Silva, M. A. A. P., Freitas, M. Q., Esmerino, E. A., Cruz, A. G., \& Pollonio, M. A. R. (2020). Adding lysine and yeast extract improves sensory properties of low sodium salted meat. Meat Science, 159, 107911. http://dx.doi. org/10.1016/j.meatsci.2019.107911. PMid:31474317.

Walsh, H., Martins, S., O’Neill, E. E., Kerry, J. P., Kenny, T., \& Ward, P. (2010). The effects of different cooking regimes on the cook yield and tenderness of non-injected and injection enhanced forequarter beef muscle. Meat Science, 84(3), 444-448. http://dx.doi.org/10.1016/j. meatsci.2009.09.014. PMid:20374808.

Wattanachant, A. S., Benjakul, S., \& Ledward, D. A. (2005). Effect of heat treatment on changes in texture, structure and properties of thai indigenous chicken muscle. Food Chemistry, 93(2), 337-348. http://dx.doi.org/10.1016/j.foodchem.2004.09.032.

White, A., O'Sullivan, A., Troy, D. J., \& O’Neill, E. E. (2006). Effects of electrical stimulation, chilling temperature and hot-boning on the tenderness of bovine muscles. Meat Science, 73(2), 196-203. http:// dx.doi.org/10.1016/j.meatsci.2005.11.020. PMid:22062289.

Wu, L. L., Luo, R. M., Kong, F., Tian, Y., \& University, N. (2016). Effect of cooking loss, tenderness and water distribution of Tan sheep at different salt addition treatment. Science and Technology of Food Industry, 37(2), 322-325.

Xia, A. Q., Li, X., Chen, L., Fan, H. E., Liu, J. K., Wang, Z. Y., Na, N. I., \& Zhang, D. Q. (2014). Effects of different pre-slaughter fasting time on mutton quality. Zhongguo Nong Ye Ke Xue, 47, 145-153.

Lu, Y., Dai, Y., Du, X., \& Dai, R. (2015). Effect of different voltages and end-point temperatures on protein degradation in lamb meat and meat quality during ohmic heating. Modern Food Science and Technology, 2, 132-137.

Zheng, C. L., Li, J. Z., Lian, X. W., \& He, C. M. (2012). Study on quality characteristics of Xinjiang native mutton skeletal muscle. Meat Industry, 2, 14-22.

Zhou, J. Y., Wang, Y. F., Li, H. W., Xie, H., \& Ding, X. L. (2003). Application of texture profile analysis in research on meat products. Food Science and Technology, (Suppl. 1), 192-195. 